\title{
ПРОЦЕДУРНЫЕ ФАКТОРЫ УСТОЙЧИВОСТИ АВТОРИТАРНЫХ РЕЖИМОВ: КОНЦЕПТУАЛЬНАЯ РАМКА АНАЛИЗА
}

\begin{abstract}
Аннотация: Предметом настоящей статьи являются функции основных стратегий политического лидера в условиях авторитарной режсиной среды. Отталкиваясь от теоретического тезиса, согласно которомуглавным процедурнылм фактором, обеспечивающим устойчивость авторитарного режима, является способность политического лидера сформировать властную коалицию, в статье фокусируется внимание на стратегических аспектах авторитарной устойчивости. Автор придерживается теоретических положений, что базовыми стратегиями формирования этой коалиции авторитарного правителя выступают кооптащия, репрессии и легитимация. В настоящей работе систематизируются основные функиии, которые выполняют указанные механизмы управления по отношению к трем основньлм политическим акторам: инсайдерам, аутсайдерам и электорату. Методологической основой анализа факторов устойчивости авторитаризма являются процедурные теории, включающие в себя неоинституциональный подход, теорию рационального выбора и конщепт неопатримониализма. В статье систематизированы основные процедурные факторы устойчивости авторитаризма, выделены и обоснованы функции трех ключевых стратегцй (кооптации, репрессий и легитимации) управления политического лидера в недемократической режимной среде. Делается вывод, что стабильность авторитаризма зависит от умения и возможности использовать лидером всех трех базовых стратегий. Только комплексное использование кооптации, репрессий и легитимаџии способно минимизировать риски, которые связаны с каждым из механизмов. Представленные теоретические положения могут быть использованы в качестве аналитической рамки анализа недемократических политических режимов.
\end{abstract}

Abstract: The object of this article involves the functions of the main strategies of the political leaders in the framework of the authoritarian regime environment. Based upon the theoretical thesis, according to which the main procedural factor guaranteeing sustainability of the authoritarian regime is an ability of a political leader to form an empowered coalition, the author concentrates on strategic aspects of totalitarian sustainability. The author supports theoretical provisions, according to which the basic strategies for coalition forming for the authoritarian ruler are cooptation, repressions and legitimation. This article systematizes the main functions performed by these administration mechanisms towards the three main political actors: insiders, outsiders and electorate. The methodological basis for the analysis of sustainability factors are procedural theories, including neo-institutional approach, theory of rational choice and neo-patrimonial concept. The article systematizes the main procedural factors for the authoritarian sustainability, the author singles out and substantiates the functions of the three key strategies for the political leader in a non-democratic regime environment-cooptation, repressions and legitimation. The conclusion is made that stability of authoritarian regime depends on the capability and possibilities for the use of all three basic strategies by the leader. Only the joint use of cooptation, repressions and legitimation may minimize the risks involved in each of them separately. The provided theoretical positions may be used as an analytic framework for analysis of non-democratic political regimes.

Ключевые слова: политические режимы, авторитаризм, прочедурные факторы, недемократические режимы, политическая устойчивость, политическая теория, диктатура, политическое развитие, политические институть, стратегия. Keywords: political regimes, authoritarianism, procedural factors, non-democratic regimes, political sustainability, political theory, dictate, political development, political institutions, strategy.

ак и в рамках теории демократизации, все концепты, объясняющие стабильность авторитарных режимов, условно можно разделить на структурные и процедурные. ${ }^{1}$ К структурным теориям принято относить такие, которые к ключевыми

\footnotetext{
${ }^{1}$ Мельвиль А.Ю. Опыт теоретико-методологического синтеза структурного и процедурного подходов к демократическим транзитам // Политические исследования. - 1998. - № 2. - С. 6-38.
}

факторам стабильности режимов относят условия объективного порядка, независимые от краткосрочных действий отдельных политических игроков. Однако для учета специфических характеристик авторитарных и гибридных режимов требуются такая оптика анализа, которая позволяет зафиксировать не только самые общие тренды, но и особенности авторитарной консолидации на уровне микрополитики. Это требует анализа стратегических действий отдельных полити- 
DOI: $10.7256 / 1811-9018.2014 .6 .12192$

При цитировании этой статьи сноска на доі обязательна

\section{Право и политика $6(174) \cdot 2014$}

ческих акторов и учета не только структурных, но и процедурных факторов. Процедурные теории ключевое внимание уделяют механизмам и стратегиям, которые применяют властвующие субъекты для удержания своего господства, а также контрмерам со стороны альтернативных элит и оппозиции, стремящихся разрушить авторитарное равновесие. Систематизация основных процедурных факторов устойчивости авторитарных режимов является основной задачей настоящей статьи.

Следуя основным положениям теории селектората Б. Буэно де Мескита, А. Смтита, Р. Сиверсона и Дж. Морроу, я исхожу из предположения, что стабильность недемократического режима зависит от способности автократа сформировать лояльную властвующую коалицию, включающую в себя основные сегменты влиятельных элит. ${ }^{2}$ Данные элитные группы в рамках исследовательской модели будут определяться как инсайдеры. Устойчивость авторитаризма также зависит от лояльности основных социальных групп (электората), степени маргинализации оппозиции и слабости элитных сегментов, не включенных в состав властвующей коалиции. Оппозицию и элиту, не инкорпорированную в систему власти, я буду обобщенно обозначать термином «аутсайдеры». Таким образом, авторитарный правитель в самом общем смысле взаимодействует с тремя политическими акторами. Это:

1. Электорат, включающий в себя самые разнообразные слои общества.

2. Инсайдеры, то есть члены элиты, инкорпорированные в состав властвующей коалиции. Они являются главной опорой режима, осуществляя поддержку правителя в обмен на выгоды, связанные с доступом к экономической ренте. Ориентация на поддержку правителя, выступающего в качестве патрона и гаранта сохранения доступа инсайдеров к ренте, формирует патрональную сеть, которая является устойчивой до тех пор, пока обмен ресурсами между правителем и инсайдером (клиентами) остается взаимовыгодным. Заинтересованность автократа в лояльности инсайдеров обуславливается наличием у них своих ресурсов и клентистской базы, по отношению к которой они выступают патронами. Именно контроль за патрональными сетями более низких этажей, которые осуществляют инсайдеры, является одним из источников массовой поддержки автократа. В целом локальные пирамидальные клиентистские сети во главе со своими патронами встраиваются в общую пирамиду, ориентированную на поддержку автократа. Эта конструкция и представляет собой патрональную сеть авторитарного правителя. Невозможность в силу различных обстоятельств сохранить стабильность патрональной сети оборачивается ослаблением авторитарного правителя и рисками потери власти.

3. Аутсайдеры, то есть оппозиционные силы и сегменты элиты вне властвующей коалиции.

Какие конкретные механизмы и стратегии используют авторитарные правители для удержания социальных групп и инсайдеров в лояльности, а аутсайдеров вне поля политического влияния?

Дж. Герчевски выделяет три ключевые стратегии автократа: легитимацию, репрессии и кооптацию. ${ }^{3}$ Следуя этим концептуальным положениям, можно выделить основные функции, которые выполняют эти стратегии по отношению к трем основным субъектам взаимодействия авторитарного лидера. В общем виде все основные функции трех основных стратегий, обеспечивающих стабильное функционирование авторитарного режима, представлены на рисунке 1.

Кооптацчия. Кооптацию можно определить как стратегические меры авторитарного правителя, направленные на формирование устойчивых связей режима с элитами и социальными группами с целью сохранения их лояльности. Данная стратегия является ключевой с точки зрения формирования властвующей коалиции.

Функиии кооптации для инсайдеров. Устойчивость властных позиций правителя прямо пропорциональна кооптационным возможностям режима и размеру властвующей коалиции. Принципиально важным является кооптация региональных элит, бюрократии силового блока и представителей бизнеса. Без удержания лояльности данной группы инсайдеров стабильное функционирование режима становится маловероятным.

Рис. 1. Функции трех стратегий авторитарного управления по отношению к основным политическим акторам

\begin{tabular}{|l|l|l|l|}
\hline Стратегии & Инсайдеры & Аутсайдеры & Электорат \\
\hline Кооптация & $\begin{array}{l}\text { Формирование лояльности и } \\
\text { сохранение элитной фрагмен- } \\
\text { тации }\end{array}$ & $\begin{array}{l}\text { Раскол и маргинализация оп- } \\
\text { позиции }\end{array}$ & $\begin{array}{l}\text { Реализация обратной связи } \\
\text { через мониторинг требова- } \\
\text { ний, идей и кадров }\end{array}$ \\
\hline
\end{tabular}

${ }_{2}^{2}$ Bueno De Mesquita, B., Smith A., Siverson R., Morrow J. M. The Logic of Political Survival. - Cambridge, MA: The MIT Press, 2003. P. 51.

\footnotetext{
${ }^{3}$ Gerschewski J. The three pillars of stability: legitimation, repression, and co-optation in autocratic regimes // Democratization. - 2013.Vol. 20. - № 1. - P. 13-38.
} 
DOI: $10.7256 / 1811-9018.2014 .6 .12192$

При цитировании этой статьи сноска на dоі обязательна

Власть и управление

\begin{tabular}{|l|l|l|l|}
\hline Репрессии & $\begin{array}{l}\text { Повышение цены нелояль- } \\
\text { ности и сохранение элитной } \\
\text { фрагментации }\end{array}$ & $\begin{array}{l}\text { Повышение цены нелояль- } \\
\text { ности и сохранение элитной } \\
\text { фрагментации }\end{array}$ & $\begin{array}{l}\text { Повышение цены политиче- } \\
\text { ской мобилизации }\end{array}$ \\
\hline Легитимация & $\begin{array}{l}\text { Сохранение лояльности на } \\
\text { основе идеи безальтернатив- } \\
\text { ности }\end{array}$ & $\begin{array}{l}\text { Сохранение лояльности на } \\
\text { основе идеи безальтернатив- } \\
\text { ности }\end{array}$ & $\begin{array}{l}\text { Формирование социальной } \\
\text { базы поддержки на основе } \\
\text { пропаганды }\end{array}$ \\
\hline
\end{tabular}

Вместе с тем, устойчивость режима зависит не только от размера властвующей коалиции, но и от формата ее элитной структуры. Хотя кооптация в состав властвующей коалиции инсайдеров создает основы для интеграции элит, чрезмерная монолитность элитных сетей создает угрозы для диктатора. Слишком сплоченная элита может легко решить проблему «коллективного действия» и объединиться против правителя. Монолитность инсайдеров становится ограничителем власти диктатора и существенно повышает риски внтуриэлитного заговора. Биполярная элитная структура властвующей коалиции также является потенциально конфликтной и нестабильной. Расколотые на две фракции элитные группы инсайдеров сохраняют статус-кво только при условии равного распределения ресурсов между ними. Однако любой дисбаланс или перемена в оценках распределения ресурсов провоцируют столкновения между элитными группами, что приводит к нестабильности режима. ${ }^{4}$ Наибольшую устойчивость авторитарному режиму обеспечивает властвующая коалиция, которая включает в себя фрагментированную элиту.

Хотя в рамках теории демократизации фрагментация элиты часто рассматривается в качестве источника конкуренции и становления формальных правил игры, содействующих институционализации демократии, ${ }^{5}$ в ситуации кооптированных элит, функционирующих в рамках патрональных сетей, фрагментированная элитная структура существенно облегчает авторитарному лидеру использовать стратегию «разделяй и властвуй» и сохранять лояльность инсайдеров. ${ }^{6}$ Поэтому логика устойчивости авторитаризма требует от правителя кооптировать во властвующую коалицию новые сегменты элит, «разбавляя» фракции для того, чтобы обеспечивать равенство их ресурсов,

${ }^{4}$ Гельман В.Я. Из огня да в полымя? (Динамика постсоветских режимов в сравнительной перспективе) // Полис. - 2007. - № 2. -C. 93-104.

${ }^{5}$ Weingast $B$. The Political Foundations of Democracy and the Rule of Law // American Political Science Review. - 1997. - Vol. 91. № 2. - P. 245-263.

${ }^{6}$ Acemoglu D., Robinson J., Verdier T. Kleptocracy and Divide and_Rule // Journal of the European Economic Association. - 2004. - Vol. 2. № 2-3. - P. 162-192. сохранение умеренной конкуренции между ними и ситуации, при которой координация и решение ими проблемы коллективных действий будет максимально затруднена. При сравнительной слабости каждой отдельной фракции возрастают возможности лидера по изменению властных позиций инсайдеров в рамках иерархии патрональной сети. Внтуриэлитная конкуренция повышает уровень недоверия между элитными сегментами и одновременно с этим создает стимулы для лояльности к правителю, который начинает выступать главным гарантом сохранения позиций инсайдеров. Следовательно, фрагментация элит в авторитарной среде увеличивает поддержку правителя со стороны инсайдеров, которые становятся заинтересованными в сохранении неизменным режимного равновесия, поскольку перспективы смещения правителя создают неопределенность и старт нового открытого противостояния между элитными фракциями, исход которого с точки зрения выгод и издержек каждой из группы конкурирующих элит просчитать очень сложно.

Таким образом, стратегия кооптации по отношению к инсайдерам может выполнять две основные функции: формирование лояльности членов властвующей коалиции и сохранение фракционности ее структуры.

Функиии кооптации для аутсайдеров. По отношению к аутсайдерам кооптация выполняет функции раскола и маргинализации оппозиции. Именно для этого многие современные авторитарные режимы используют в своей конструкции формальные каналы, такие как партии, легислатуры и выборы. ${ }^{7} \mathrm{C}$ помощью этих институтов режим кооптирует часть оппозиционных акторов в состав властвующей коалиции, что приводит к расколу и ослаблению оппозиционных сил. В условиях электорального авторитаризма, ${ }^{8}$ ключевой проблемой инкумбента является способность интеграции оппозиции и возможность выступления единым

\footnotetext{
${ }^{7}$ Gandhi J., Przeworski A. Authoritarian institutions and survival of autocrats // Comparative political studies. - 2007. - Vol. 40. - № 11. - P. 1279-1301.

${ }^{8}$ Schedler $A$. The logic of electoral authoritarianism // Electoral Authoritarianism: The Dynamics of Unfree Competition / ed. by A. Schedler. Boulder, CO, und London, UK: Lynne Rienner Publishers, 2006. P. 1-23.
} 
DOI: $10.7256 / 1811-9018.2014 .6 .12192$

При цитировании этой статьи сноска на доі обязательна

\section{Право и политика $6(174) \cdot 2014$}

политическим блоком. ${ }^{9}$ Частичное кооптирование членов оппозиции, посредством предоставления им мест в представительных органах власти, приводит к расколу оппозиции и формированию ее дуалистической структуры, состоящей, по терминологии Х. Линца, из принципиальной оппозиции (несистемной) и лояльной полуоппозиции (системной). ${ }^{10}$ В результате стратегии кооптации режим добивается маргинализации оппозиционных сил, в том смысле, что, потеряв стимулы к координации, они теряют способность составить электоральную конкуренцию инкумбенту. Члены лояльной полуоппозиции получают только минимум властных позиций, не позволяющий им существенно влиять на политический курс. Принципиальная оппозиция вообще вытесняется за рамки институционального политического пространства и единственной возможной для нее стратегией политической борьбы остается протестная деятельность. Однако в силу раскола и фрагментации, «несистемная» оппозиция ограничена в своих возможностях массовой мобилизации и ее попытки создать угрозу режиму с помощью акций прямого действия легко купируются точечными репрессиями.

Более того, интеграция части автономных акторов на правах «системной оппозиции» во властвующую коалицию создает логику политической игры, в рамках которой у оппозиционных акторов возникают стимулы конкурировать друг с другом, а не с инкумбентом. Члены лояльной полуоппозиции, удерживающие места в легислатуре благодаря картельным договоренностям с властью, становятся незаинтересованными в расширении конкуренции и демократизации, поскольку их запуск является угрозой их положению. В случае увеличения роли электората в определении сил, получающих властные позиции, значительная доля мест (если не все полностью) в легислатуре, удерживаемых членами «системной» оппозиции, могут отойти представителям «несистемной» оппозиции. В результате члены лояльной полуоппозиции становятся верной поддержкой режима, а их позиция - существенным ограничителем расширения политических свобод и конкуренции.

Функици кооптацุии для электората. Одной из главных проблем недемократических режимов является их слабая обратная связь с обществом. В отсут-

\footnotetext{
${ }^{9}$ Bunce V. J. Wolchik S. L. Defeating Dictators: Electoral Change and Stability in Competitive Authoritarian Regimes // World Politics. 2010. - Vol. 62.- № 1. - P. 43-86.

${ }^{10}$ Linz J. Opposition to and under an Authoritarian Regime: The Case of Spain // Regimes and Oppositions. R.Dahl (ed.). - New Haven and London: Yale University Press, 1978. P.191.
}

ствии конкурентных выборов и ротации элит, режим становится нечувствительным к смене общественных настроений и испытывает затруднения в объективной оценке целевых ориентиров различных социальных групп. Кооптация более широких слоев населения в различные формальные структуры частично может решить эти проблемы. Для этого режим создает различного рода организации - от подконтрольных политических партий и общественных движений, до Общественных палат и Ассамблей народов, - призванных интегрировать более широкие социальные слои для налаживания контактов с государственными органами власти и обмена информацией между ними. Власть также формирует разного рода механизмы рекрутации и селекции (Молодежные парламенты, молодежные движения, кадровые резервы) для отбора кадров, решая задачу восполнения элит. Все эти органы носят корпоративный, а не демократический характер, поскольку не имеют автономии от власти и не выполняют функции конкуренции с властвующими субъектами. Таким образом, без угрозы своей монополии, режим обеспечивает мониторинг новых идей, перспективных кадров и создает каналы обратной связи с обществом.

Репрессии. Под репрессиями в политической науке чаще всего понимаются «действия или угрозы применения физических санкций против отдельных лиц или организаций, в рамках территориальной юрисдикции государства, с целью повышения цены на политическую деятельность, а также для пресечения оппозиционных мероприятий или убеждений». ${ }^{11}$ Я следую более широкому пониманию репрессий в трактовке Р. Винтроба, который в это понятие вкладывает не только действия или угрозы физической расправы, но и любые меры, ограничивающие политические свободы граждан. ${ }^{12}$

Функиии репрессий для инсайдеров. Как следует из классического определения репрессий, основной функцией данной стратегии власти является повышение цены на политическую деятельность. Для инсайдеров это означает повышение цены их выбора в пользу нелояльной деятельности относительно автократа. Поскольку внтуриэлитный переворот часто является для диктатора важнейшей угрозой, репрессии призваны максимально повысить издержки для инициаторов или потенциальных участников возможного заговора.

\footnotetext{
${ }^{11}$ Goldstein R. Political Repression in Modern America: from 1870 to the Present. - Cambridge, MA: Schenkman, 1978. P. 27; Davenport C. State Repression and Political Order // Annual Review of Political Science. - 2007. - № 10. - P. 2.

${ }^{12}$ Wintrobe R. The political economy of dictatorship. - New York: Cambridge University Press, 1998. P. 34.
} 
Кроме того, репрессии необходимы авторитарному правителю с целью сохранения элитной фрагментации. Как уже указывалось выше, фрагментированная элитная структура выступает одним из условий стабильного положения автократа. Посредством репрессий диктатор ослабляет усилившихся претендентов, производит ротации и кадровые перестановки с целью предотвратить монолитность элит и расширить свое пространство для проведения политики в стиле «разделяй и властвуй». ${ }^{13}$

Функиии репрессий для аутсайдеров. По отношению к аутсайдерам репрессии выполняют функции повышения цены антиправительственной деятельности, а также служат механизмом сохранения раскола оппозиции. Создав дуальную структуру оппозиционных акторов и включив в состав властвующей коалиции «системную» оппозицию, с помощью репрессий режим удерживает последнюю от попыток выйти изпод контроля и объединится с блоком «несистемной» оппозиции, вероятность чего возникает в моменты экономического кризиса или других ситуациях общей нестабильности развития общества.

Функиии репрессий для электората. Репрессии по отношению к электорату направлены для повышения цены поддержки оппозиции. Не менее важной функцией репрессий является удержание социальных групп от участия в массовых протестных акциях. Наряду с рисками внтутриэлитного заговора, политическая мобилизация и протестная активность снизу является для недемократических режимов наиболее опасной угрозой. Именно для удержания общества от массовой мобилизации режим использует методы устрашения и репрессий по отношению к более широкому кругу лиц, чем только оппозиционные политики и активисты.

Легитимация. Хотя в рамках изучения тоталитаризма механизмы легитимации режима были в центре внимания исследователей, в большинстве новых теорий авторитаризма данный аспект находятся на периферии исследовательского интереса. Достаточно распространенной стала точка зрения, согласно которой легитимация не имеет существенного значения для авторитарного лидера, поскольку его власть не опирается на мнение большинства народа. В тоже время, современные политические реалии, связанные с глобализацией и информатизацией, делают идеологические и легитимационные аспекты устойчивости авторитаризма не менее важными. Стратегии кооптации и репрессий требуют существенных экономических

${ }^{13}$ Acemoglu D., Robinson J., Verdier T. Kleptocracy and Divide and Rule // Journal of the European Economic Association. - 2004. Vol. 2. № 2-3. - P. 162-192. ресурсов, что делает функционирование режима, основанного только на этих механизмах, слишком затратным. Дж. Герчевски рассматривает легитимацию как важнейшую опору современных форм авторитаризма, интегрируя данную стратегию, наравне с кооптацией и репрессиями, в разработанную им аналитическую рамку исследования устойчивости автократии. ${ }^{14}$ Следуя его методологическим положениям, можно определить легитимацию как механизмы инкумбента, направленные на структурирование связей между властью и обществом с целью формирования активной поддержки, соблюдения установленных правил, пассивного послушания или просто терпимости к власти со стороны элит и широких социальных слоев.

Сами механизмы легитимационных практик могут быть весьма многообразными, включающими в себя индоктринацию идеологических систем правого или левого толка, использование националистических или религиозных идеологем, культивацию популизма и харизмы лидера, позиционирование экономических успехов режима, формирование с помощью пропаганды чувства страха и стереотипов врага у населения с целью убеждения в необходимости ужесточения режима ради сохранения безопасности общества и т. д. В целом все разнообразие этих мер объединяет основная цель режима в виде убеждения основных социальных субъектов в целесообразности сохранения существующей конструкции власти и справедливости нахождения у ее вершины соответствующих правителей. В тоже время, функции легитимации по отношению к разным политическим акторам имеют свою специфику.

Функиии легитимации для инсайдеров. Легитимация по отношению к инсайдерам носит сугубо прагматический характер, формируя убеждение среди элит в целесообразности сохранения автократа у власти в качестве лучшей из возможных гарантий стабильности их позиций и выгод. Легитимация в данном случае выступает не столько как идеология или набор ценностей, сколько неформальный элитный договор о разделе сфер влияния и обязательствах по распределению ренты. Стабильность диктатора сохраняется до тех пор, пока основные элитные сегменты властвующей коалиции сохраняют убеждение, что существующий правитель служит их интересам, обеспечивает безопасность их положения и минимизирует риски посягательств на их позиции, как со стороны конкурирующих элитных фракций, так и со стороны аутсайдеров.

\footnotetext{
${ }^{14}$ Gerschewski $J$. The three pillars of stability: legitimation, repression, and co-optation in autocratic regimes // Democratization. - 2013. - Vol. 20. - No. 1. - P. 13-38.
} 
DOI: $10.7256 / 1811-9018.2014 .6 .12192$

При цитировании этой статьи сноска на доі обязательна

\section{Право и политика $6(174) \cdot 2014$}

Функиии легитимации для аутсайдеров. Как указывают В. Бансе и С. Волчик, одной из проблем оппозиционных акторов в авторитарной среде является отсутствие веры в наличии шансов победить инкумбента. ${ }^{15}$ Распространение пессимизма среди оппозиции ведет к пассивности и ошибкам в стратегическом планировании политической борьбы. Функции легитимации для аутсайдеров заключаются в формировании этого пессимизма и развитии убеждения, основанного на идеи непобедимости авторитарного лидера. Для этого используются как средства пропаганды, так и электоральные практики. Б. Магалони на опыте политического развития Мексики убедительно раскрывает причины необходимости автократам добиваться не просто электорального превосходства над оппозицией, но делать это с существенно преобладающим перевесом. С ее точки зрения, тем самым режим легитимизирует свое господство, демонстрируя, что власть инкумбентов опирается на массовую поддержку. При этом эта поддержка настолько очевидная, что у оппозиции нет никаких шансов на успех. Сохранение пессимизма у оппозиции в результате подобных электоральных практик сохраняет интеграцию инсайдеров и удерживает потенциально оппозиционный бизнес от поддержки аутсайдеров. ${ }^{16}$ Власть заинтересована сохранять имидж оппозиции как жалких неудачников, не имеющих никакой социальной базы и политических перспектив. Это, в свою очередь, влияет на оппозиционную среду, в рамках которой сохраняется пессимизм и, как следствие, менее наступательная стратегия действий и недооценка своих возможностей.

Функиии легитимации для электората. Как уже указывалось выше, устойчивость современных авторитарных режимов редко основывается только исключительно на «страхе и подкупе». По крайней мере для более долговременной стабильности автократиям, как и демократиям, необходима массовая поддержка. Специфика недемократических режимов заключается в том, что социальная база формируется не посредством конкурентных выборов, а с помощью пропаганды и средствами политических технологий. Инкумбенты могут использовать широкий набор идеологем, главной целью которых является убеждение электората в полезности и справедливости существующей власти.

\footnotetext{
${ }^{15}$ Bunce V. J. Wolchik S. L. Defeating Dictators: Electoral Change and Stability in Competitive Authoritarian Regimes // World Politics. 2010. - Vol. 62.- № 1. - P. 67.

${ }^{16}$ Magaloni B. Voting for Autocracy: Hegemonic Party Survival and Its Demise in Mexico. - Cambridge, UK: Cambridge University Press, 2006. P. 7-10.
}

Например, в рамках постсоветского политического развития наиболее распространенными из них стали идеи национализма и девелопментанизма (от англ. Development - развитие). Под последним термином имеется в виду культивацию режимом идеи развития, означающую экономический прогресс, поступательный рост и эффективность. Не мене активно используются, часто создаваемые искусственно, социальные фобии угрозы общественной дестабилизации. Авторитарные правители легитимизируют свою власть в глазах электората с помощью позиционирования себя в качестве единственных гарантов стабильности, безопасности и защиты от разного рода внутренних и внешних врагов, стереотипы которых активно создаются методами пропаганды.

Кроме того, авторитарные режимы часто эффективно используют демократические элементы в качестве легитимации. В частности, институты выборов или референдумы служат для автократов средством демонстрации своей массовой поддержки. Хотя они проводятся без соблюдения базовых принципов равенства и справедливости конкуренции, а элементы политического соперничества не выходят за рамки «виртуальной политики», ${ }^{17}$ убедительные электоральные результаты имеют существенное значение для сохранения лояльности большой доли аполитичных граждан, составляющих основу «медианного избирателя». Именно эта часть электората цементирует «авторитарное большинство», с помощью которого режим приобретает устойчивость и минимизирует риски массовой политической мобилизации. ${ }^{18}$

Завершая рассмотрение основных функций трех главных стратегий, определяющих устойчивость авторитарной власти, следует отметить, что стабильность авторитаризма зависит от умения и возможности использовать лидером всего спектра этих средств. Другими словами, «идеальная диктатура» основывается не на отдельных механизмах, а на всем их комплексе и возможности автократа эффективно варьировать ими в зависимости от динамики политического процесса. Проблема для авторитарного правителя заключается в том, что каждая из рассмотренных стратегий несет в себе определенные издержки и угрозы. Только комплексное использование кооптации, репрессий и легитимации способно минимизировать риски, которые связаны с каждым из механизмов.

\footnotetext{
${ }^{17}$ Wilson A. Virtual Politics: Faking Democracy in the Post-Soviet World. - New Haven and London: Yale University Press, 2005.

${ }^{18}$ Рогов К. Сверхбольшинство для сверхпрезидентства // Pro et Contra. - 2013. - T. 7. - № 3-4. - C. 102-125.
} 
DOI: $10.7256 / 1811-9018.2014 .6 .12192$

При цитировании этой статьи сноска на doi обязательна

Власть и управление

\section{Библиография:}

1. Гельман В.Я. Из огня да в полымя? (Динамика постсоветских режимов в сравнительной перспективе) // Полис. - 2007. - № 2, -C. 81-108.

2. Мельвиль А.Ю. Опыт теоретико-методологического синтеза структурного и процедурного подходов к демократическим транзитам // Политические исследования. - 1998. - № 2. - С. 6-38.

3. Рогов К. Сверхбольшинство для сверхпрезидентства // Pro et Contra. - 2013. - Т. 7. - № 3-4. - C. 102-125.

4. И.М. Соколов. Эффективность государственных решений в условиях модернизации: опыт стран мира // Тренды и управление. - 2013. - № 2. C. 104-107. DOI: 10.7256/2307-9118.2013.2.4951

5. Шмидт Т.Н.. Теоретико-правовое обоснование чрезвычайного правового регулирования и доктрина «исключительного положения» // Политика и Общество. - 2013. - № 9. - С. 104-107. DOI: 10.7256/1812-8696.2013.9.9482

6. Карпович О.Г.. Демократизация в современных концепциях российских и американских исследователей // Национальная безопасность / nota bene. - 2013. - № 3. - C. 104-107. DOI: 10.7256/20738560.2013.3.8083

7. 7. Р.Н. Пархоменко. Дихотомия политического К. Шмитта // Психология и Психотехника. -2013. № 4. - C. 104-107. DOI: 10.7256/2070-8955.2013.04.9

8. М.А. Крупский. Переосмысление феномена социальной аномии в условиях современного общества (опыт России) // Политика и Общество. - 2012. - № 12. - С. 104-107.

9. А. А. Борисенков. Политический процесс - ход политического влияния // Политика и Общество. - 2012. - № 8. - С. 104-107.

10. А.А. Борисенков. Понятие политической культуры // Философия и культура. - 2012. - № 5. - С. 104-107.

11. С.А. Королев. Микросоциумы в российском пространстве власти // Философия и культура. - 2011. - № 6. - С. 104-107.

12. А. А. Борисенков. Политический режим - способ политического влияния // Политика и Общество. - 2011. - № 5.

13. С. В. Попов. Российская власть и парламентская оппозиция в 2000-е гг. // Политика и Общество. 2011. - № 8. - C. 104-107.

14. Acemoglu D., Robinson J., Verdier T. Kleptocracy and Divide and_Rule // Journal of the European Economic Association. - 2004. - Vol. 2. № 2-3. - P. 162-192.
15. Bueno De Mesquita, B., Smith A., Siverson R., Morrow J. M. The Logic of Political Survival. - Cambridge, MA: The MIT Press, 2003. - 536 p.

16. Bunce V. J. Wolchik S. L. Defeating Dictators: Electoral Change and Stability in Competitive Authoritarian Regimes // World Politics. - 2010. - Vol. 62. - № 1. - P. 43-86.

17. Davenport C. State Repression and Political Order// Annual Review of Political Science. - 2007. - № 10. - P. 1-23.

18. Gandhi J., Przeworski A. Authoritarian institutions and survival of autocrats // Comparative political studies. - 2007. - Vol. 40. - № 11. - P. 1279-1301.

19. Gerschewski J. The three pillars of stability: legitimation, repression, and co-optation in autocratic regimes // Democratization. - 2013. - Vol. 20. -№ 1. - P. 13-38.

20. Goldstein R. Political Repression in Modern America: from 1870 to the Present. - Cambridge, MA: Schenkman, 1978. $-682 \mathrm{p}$.

21. Linz J. Opposition to and under an Authoritarian Regime: The Case of Spain // Regimes and Oppositions. R.Dahl (ed.). - New Haven and London: Yale University Press, 1978. P.171-259.

22. Magaloni B. Voting for Autocracy: Hegemonic Party Survival and Its Demise in Mexico. - Cambridge, UK: Cambridge University Press, 2006. - 296 p

23. Schedler A. The logic of electoral authoritarianism // Electoral Authoritarianism: The Dynamics of Unfree Competition / ed. by A. Schedler. Boulder, CO, und London, UK: Lynne Rienner Publishers, 2006. P. 1-23.

24. Weingast B. The Political Foundations of Democracy and the Rule of Law // American Political Science Review. - 1997. - Vol. 91. - № 2. - P. 245-263.

25. Wilson A. Virtual Politics: Faking Democracy in the Post-Soviet World. - New Haven and London: Yale University Press, 2005. - 332 p.

26. Wintrobe R. The political economy of dictatorship. New York: Cambridge University Press, 1998. - 390 p.

\section{References (transliteration):}

1. Gel'man V.Ya. Iz ognya da v polymya? (Dinamika postsovetskikh rezhimov v sravnitel'noi perspektive) // Polis. - 2007. - № 2, -S. 81-108.

2. Mel'vil' A.Yu. Opyt teoretiko-metodologicheskogo sinteza strukturnogo i protsedurnogo podkhodov $\mathrm{k}$ demokraticheskim tranzitam // Politicheskie issledovaniya. - 1998. - № 2. - S. 6-38.

3. Rogov K. Sverkhbol'shinstvo dlya sverkhprezidentstva // Pro et Contra. - 2013. - T. 7. - № 3-4. - S. 102-125. 
DOI: $10.7256 / 1811-9018.2014 .6 .12192$

При цитировании этой статьи сноска на dоі обязательна

\section{Право и политика $6(174) \cdot 2014$}

4. I.M. Sokolov. Effektivnost' gosudarstvennykh reshenii v usloviyakh modernizatsii: opyt stran mira // Trendy i upravlenie. - 2013. - № 2. - S. 104-107. DOI: 10.7256/2307-9118.2013.2.4951

5. Shmidt T.N.. Teoretiko-pravovoe obosnovanie chrezvychainogo pravovogo regulirovaniya i doktrina «isklyuchitel'nogo polozheniya» // Politika i Obshchestvo. - 2013. - № 9. - S. 104-107. DOI: 10.7256/1812-8696.2013.9.9482

6. Karpovich O.G.. Demokratizatsiya v sovremennykh kontseptsiyakh rossiiskikh i amerikanskikh issledovatelei // Natsional'naya bezopasnost' / nota bene. - 2013. - № 3. - S. 104-107. DOI: 10.7256/20738560.2013.3.8083

7. R.N. Parkhomenko. Dikhotomiya politicheskogo K. Shmitta // Psikhologiya i Psikhotekhnika. - 2013. № 4. - S. 104-107. DOI: 10.7256/2070-8955.2013.04.9

8. M.A. Krupskii. Pereosmyslenie fenomena sotsial'noi anomii v usloviyakh sovremennogo obshchestva (opyt Rossii) // Politika i Obshchestvo. - 2012. - № 12. S. 104-107.

9. A. A. Borisenkov. Politicheskii protsess - khod politicheskogo vliyaniya // Politika i Obshchestvo. 2012. - № 8. - S. 104-107.

10. A.A. Borisenkov. Ponyatie politicheskoi kul'tury // Filosofiya i kul'tura. - 2012. - № 5. - S. 104-107.

11. S.A. Korolev. Mikrosotsiumy v rossiiskom prostranstve vlasti // Filosofiya i kul’tura. - 2011. - № 6. S. 104-107.

12. A. A. Borisenkov. Politicheskii rezhim - sposob politicheskogo vliyaniya // Politika i Obshchestvo. 2011. - № 5.

13. S. V. Popov. Rossiiskaya vlast' i parlamentskaya oppozitsiya v 2000-e gg. // Politika i Obshchestvo. - 2011. - № 8. - S. 104-107.

14. Acemoglu D., Robinson J., Verdier T. Kleptocracy and Divide and_Rule // Journal of the European Economic Association. - 2004. - Vol. 2. № 2-3. - P. 162-192.
15. Bueno De Mesquita, B., Smith A., Siverson R., Morrow J. M. The Logic of Political Survival. - Cambridge, MA: The MIT Press, 2003. - $536 \mathrm{p}$.

16. Bunce V. J. Wolchik S. L. Defeating Dictators: Electoral Change and Stability in Competitive Authoritarian Regimes // World Politics. - 2010. - Vol. 62. - № 1. - P. 43-86.

17. Davenport C. State Repression and Political Order // Annual Review of Political Science. - 2007. - № 10. - P. 1-23.

18. Gandhi J., Przeworski A. Authoritarian institutions and survival of autocrats // Comparative political studies. - 2007. - Vol. 40. - № 11. - P. 1279-1301.

19. Gerschewski J. The three pillars of stability: legitimation, repression, and co-optation in autocratic regimes // Democratization. - 2013. - Vol. 20. -№ 1. - P. 13-38.

20. Goldstein R. Political Repression in Modern America: from 1870 to the Present. - Cambridge, MA: Schenkman, 1978. $-682 \mathrm{p}$.

21. Linz J. Opposition to and under an Authoritarian Regime: The Case of Spain// Regimes and Oppositions. R.Dahl (ed.). - New Haven and London: Yale University Press, 1978. P.171-259.

22. Magaloni B. Voting for Autocracy: Hegemonic Party Survival and Its Demise in Mexico. - Cambridge, UK: Cambridge University Press, 2006. - 296 p.

23. Schedler A. The logic of electoral authoritarianism // Electoral Authoritarianism: The Dynamics of Unfree Competition / ed. by A. Schedler. Boulder, CO, und London, UK: Lynne Rienner Publishers, 2006. P. 1-23.

24. Weingast B. The Political Foundations of Democracy and the Rule of Law // American Political Science Review. - 1997. - Vol. 91. - № 2. - P. 245-263.

25. Wilson A. Virtual Politics: Faking Democracy in the Post-Soviet World. - New Haven and London: Yale University Press, 2005. $-332 \mathrm{p}$.

26. Wintrobe R. The political economy of dictatorship.New York: Cambridge University Press, 1998. - 390 p. 